\title{
Aplikasi Filosofi Tri Hita Karana dalam Konsep Perencanaan Lansekap Gereja Katolik Santa Maria Immaculata, Tabanan
}

\author{
IVANNA WISNU WARDANI ${ }^{1}$, A.A. GEDE DALEM SUDARSANA ${ }^{1 *}$, \\ SANG MADE SARWADANA ${ }^{1}$
}

1. Program Studi Arsitektur Pertamanan, Fakultas Pertanian, Universitas Udayana, Jl.

PB. Sudirman Denpasar, 80362, Bali

*E-mail:agungdalems@gmail.com

\section{ABSTRACT \\ Tri Hita Karana as Site Plan Concepts of Santa Maria Immaculata Catholic Church Tabanan Landscape}

Santa Maria Immaculata Catholic Church Tabanan (SMICCT) landscape has been developed for sufficient the user activities. There is no particular site plan concept, therefore SMICCT garden is not well ordered. This research aims to apply Tri Hita Karana (THK) as SMICCT site plan concept, to adjust THK with the user activities and apply the garden elements that unify the characters of THK. The results of this research showed that SMICCT landscape needs to be structured the garden to create a space and provide atmosphere which contains the activities of users. THK as SMICCT site plan concepts are used to categorize the space based on the user activities, and to choose garden elements in creating the atmosphere of space on the SMICCT landscape.

Keywords: cultural inculturation, tri hita karana, site plan

\section{Pendahuluan}

\subsection{Latar Belakang}

Gereja Katolik Santa Maria Immaculata Tabanan (GKSMIT) berlokasi di Kabupaten Tabanan, Bali. Lansekap GKSMIT saat ini telah mengalami revitalisasi dan adaptasi untuk mewadahi kegiatan umat GKSMIT. Kondisi taman pada lansekap terlihat tidak tertata dan tidak terawat. Berdasarkan kondisi tersebut, penulis berinisiatif untuk mengaplikasikan THK sebagai konsep dasar perencanaan lansekap GKSMIT.

Tujuan dari penelitian adalah untuk mengaplikasikan THK sebagai konsep perencanaan lansekap GKSMIT yang sesuai dengan kegiatan umat GKSMIT serta membuat rekomendasi taman.

\section{Bahan dan Metode}

Penelitian dilaksanakan dari bulan Januari - Mei 2014, berlokasi di jalan Singosari 3A Tabanan. Jenis penelitian merupakan deskriptif kualitatif dengan metode survei. Alat 
pengumpulan data adalah lembar kuesioner, kamera digital, alat ukur meteran, dan komputer untuk mengolah data menggunakan software Microsoft Excel 2007, Adobe Photoshop CS 3 dan Autocad 2011. Metode pengumpulan data meliputi metode studi pustaka, observasi, wawancara dan kuesioner. Besar sampel kuesioner sebanyak 100 responden. Metode analisis data yang digunakan dalam penelitian ini adalah metode analisis destriptif komparatif. Metode dalam perencanaan lansekap tersebut meliputi persiapan tapak, inventarisasi data tapak, analisis sintesis dan perencanaan.

\section{Hasil dan Pembahasan}

\subsection{Data Inventaris GKSMIT}

GKSMIT didesain oleh seorang arsitektur beragama Katolik bernama Prof. Dr. Sulistyawati, M.Sc dengan mencerminkan budaya Bali (Mugi, 2011 b). Pemilihan tanaman pada lansekap GKSMIT tanpa konsep atau pedoman tertentu dari gereja Katolik, sehingga kualitas estetika pemandangan menjadi kurang baik (bad view). Fasilitas yang terdapat di GKSMIT yaitu tempat parkir mobil, tempat parkir motor, gazebo dan toilet. Gambar 1-3 menunjukkan kondisi estetika pemandangan dalam lansekap GKSMIT.

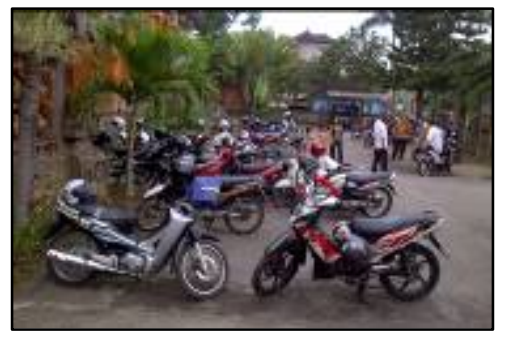

Gambar 1. Kondisi di Area Masuk GKSMIT

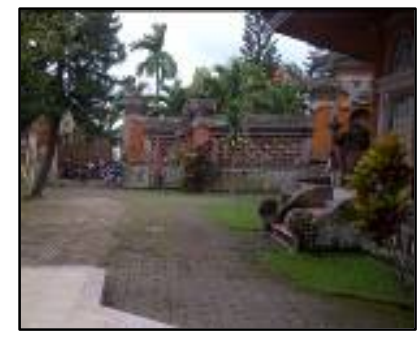

Gambar 2. Kondisi di Area Suci GKSMIT

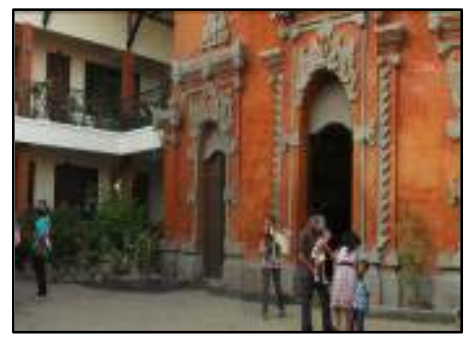

Gambar 3. Kondisi di Area Sekretariat GKSMIT

\subsection{Data Pengguna GKSMIT}

Jumlah umat GKSMIT tercatat pada tahun 2010 sebanyak 1250 jiwa. Kegiatan yang dilaksanakan pada lansekap GKSMIT dikategorikan menjadi dua jenis kegiatan utama, yaitu kegiatan keagamaan dan kegiatan sosial.

Penilaian terhadap rasa nyaman pengguna menunjukkan bahwa, 55\% responden menyatakan nyaman berada di kawasan lansekap GKSMIT. Namun sebanyak 48\% responden menyatakan bahwa, perlu dilakukan perbaikan pada kawasan GKSMIT. Sebanyak 38\% responden menyatakan perlunya perbaikan kurangnya tanaman.

Hasil kuesioner menunjukkan bahwa, sebanyak 94\% responden menyatakan setuju bahwa THK merupakan produk kebudayaan masyarakat Bali. Pemahaman umat GKSMIT terhadap THK dilanjutkan ke dalam bentuk pembagi ruang (zonasi) di lansekap GKSMIT. Parahyangan, sebanyak 98\% responden menyatakan implementasi unsur ini di area bangunan utama GKSMIT dan 47\% menyatakan kegiatan di ruang ini adalah perayaan Misa Ekaristi. Pawongan, sebanyak sebanyak 78\% responden menyatakan implementasi unsur ini di area aula GKSMIT dan responden menyatakan kegiatan di ruang ini adalah kegiatan OMK (33\%) serta latihan koor (32\%). Palemahan, sebanyak sebanyak 64\% 
respoonden menyatakan implementasi unsur ini di area masuk GKSMIT dan 53\% menyatakan kegiatan di ruang ini adalah kegiatan kerja bakti.

\subsection{Analisis dan Sintesis Lansekap GKSMIT}

\subsubsection{Data Inventaris GKSMIT}

Lansekap GKSMIT tidak ada konsep khusus untuk tata ruangnya. Kondisi ini menyebabkan penataan elemen, khususnya elemen taman, hanya bersifat dekoratif saja. Konsep penataan ruang pada lansekap GKSMIT ditata dengan konsep budaya Bali agar tercipta suasana sesuai dengan konsep awal bangunan utama. Konsep tersebut tidak bertentangan dengan ajaran agama Katolik sesuai dengan hasil keputusan dalam Dokumen Konstitusi Vatican II (Paulus Uskup Gereja Katolik, 1963).

Pemilihan tanaman tanpa konsep penataan dan tidak mewakili simbol-simbol dari gereja Katolik. Perlu menambah tanaman berbunga yang memiliki peran sebagai simbol gereja, dan dapat dimanfaatkan pada saat upacara keagamaan. Menurut Fireza (2008), pemilihan tanaman sebagai simbol berdasarkan pedoman Kitab Suci dan pemahaman dari gereja Katolik dapat mewakili suasana dalam Liturgi.

Kondisi tempat parkir mobil kurang maksimal, karena jarak parkir tidak teratur, sehingga perlu garis pembatas jarak parkir lebih teratur. Penataan kendaraan di tempat parkir motor GKSMIT kurang rapi, sehingga pembuatan blok-blok penempatan motor berupa garis. Kondisi fisik gasebo masih dalam kondisi sangat baik, namun sekitar gazebo terasa panas sehingga diperlukan tanaman peneduh. Toilet dalam kondisi baik tetapi tidak ada tanaman dan terasa gersang, sehingga perlu taman dengan fungsi memperlembut perkerasan dan memperindah pemandangan di sekitar bangunan toilet.

\subsubsection{Penggunaan Ruang pada Lansekap GKSMIT}

Berdasarkan kegiatan pengguna dalam lansekap GKSMIT dan hasil kuesioner, penggunaan ruang dikelompokkan menjadi tiga blok ruang, yaitu:

1) Ruang kegiatan sakral, terletak di area bangunan utama GKSMIT sebagai tempat untuk umat GKSMIT melaksanakan kegiatan keagamaan.

2) Ruang kegiatan sosial, terletak di area aula GKSMIT sebagai tempat bagi umat GKSMIT melakukan kegiatan sosial.

3) Ruang kegiatan servis, terletak di area masuk GKSMIT merupakan area fasilitas pendukung diletakkan. Kegiatan yang dilakukan oleh umat GKSMIT pada ruang ini meliputi menjaga kebersihan, merawat tanaman dan penghijauan. Ruang ini.

Sintesis terhadap pembagian ruang di lansekap GKSMIT yaitu penggunaan konsep tata ruang yang jelas agar pengguna merasa nyaman. Suasana ruang yang tepat dapat memberi pengaruh kepada pengguna lansekap secara fisik maupun emosional (Simond, 1983).

\subsection{Konsep Dasar Perencanaan GKSMIT}

Konsep dasar perencanaan lansekap GKSMIT dibuat berdasarkan tujuan untuk menciptakan suasana yang mendukung kegiatan umat GKSMIT. Hasil kuesioner menujukkan bahwa, 96\% responden menyatakan konsep awal pada bangunan utama 
GKSMIT mencerminkan budaya Bali. Berdasarkan penjelasan di atas, THK sesuai untuk diaplikasikan sebagai konsep dasar perencanaan lansekap GKSMIT karena merupakan produk dari budaya masyarakat Bali.

\subsubsection{Konsep Tata Ruang}

THK merupakan suatu produk dari budaya masyarakat Bali yang berupa sistem budaya. Sesuai dengan pernyataan Koentjaraningrat (1997), yaitu suatu kebudayaan dapat berupa gagasan yang berpola dan berdasarkan suatu sistem. Proses aplikasi THK sebagai konsep tata ruang yaitu dengan menyesuaikan unsur-unsur dalam THK dengan kegiatan yang terdapat di dalam tiga blok ruang pada lansekap GKSMIT. Penyesuaian unsur-unsur THK yang ditampilkan pada Tabel 1.

Tabel 1. Penyesuaian Unsur THK

\begin{tabular}{cllc}
\hline $\begin{array}{c}\text { Blok Ruang } \\
\text { GKSMIT }\end{array}$ & \multicolumn{1}{c}{ Karakter Ruang GKSMIT } & Unsur THK \\
\hline$(1)$ & \multicolumn{1}{c}{$(2)$} & $(3)$ \\
\hline Sakral & a. & $\begin{array}{l}\text { Kegiatan keagamaan, meliputi berdoa, mengikuti misa Ekaristi, } \\
\text { pengakuan doa, membaca alkitab }\end{array}$ & Parahyangan \\
& b. $\begin{array}{l}\text { Suasana ruang: suci, tenang dan merenung } \\
\text { Sosial }\end{array}$ & a. $\begin{array}{l}\text { Kegiatan sosial, meliputi kegiatan OMK, kegiatan WKRI, latihan } \\
\text { koor dan bakti sosial }\end{array}$ & Pawongan \\
& b. Suasana ruang: aktif, berkumpul dan santai & \\
\hline \multirow{2}{*}{ Servis } & a. $\begin{array}{l}\text { Kegiatan yang bersifat memanfaatkan fasilitas dan mencaga } \\
\text { kebersihan lingkungan }\end{array}$ & Palemahan \\
& b. Suasana ruang: tenang dan menyegarkan & \\
\hline
\end{tabular}

\subsubsection{Konsep Tata Hijau}

Konsep tata hijau yang dikembangkan bertemakan tanaman simbolis gereja Katolik, untuk menonjolkan nilai spiritual dalam lansekap GKSMIT. Simbolis dalam lingkungan gereja dapat membawa umat ke dalam realita Illahi dan keagungan perayaan liturgi (Martasudjita, 1998). Jenis tanaman yang digunakan yaitu tanaman selalu hijau sepanjang tahun (evergreen conifers). Warna tanaman yang dipilih mewakili warna-warna liturgi. Tabel 2 menjelaskan fungsi, kriteria dan contoh tanaman yang digunakan.

Tabel 2. Fungsi, Kriteria dan Contoh Tanaman pada Lansekap GKSMIT

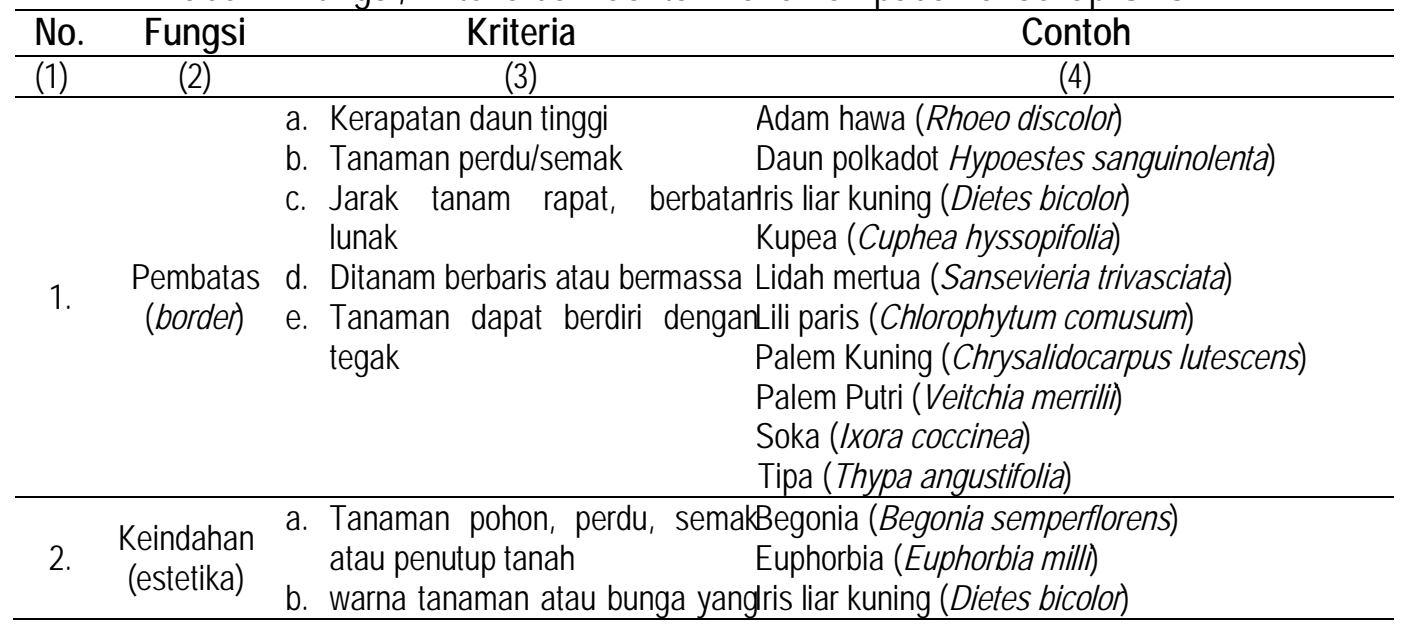




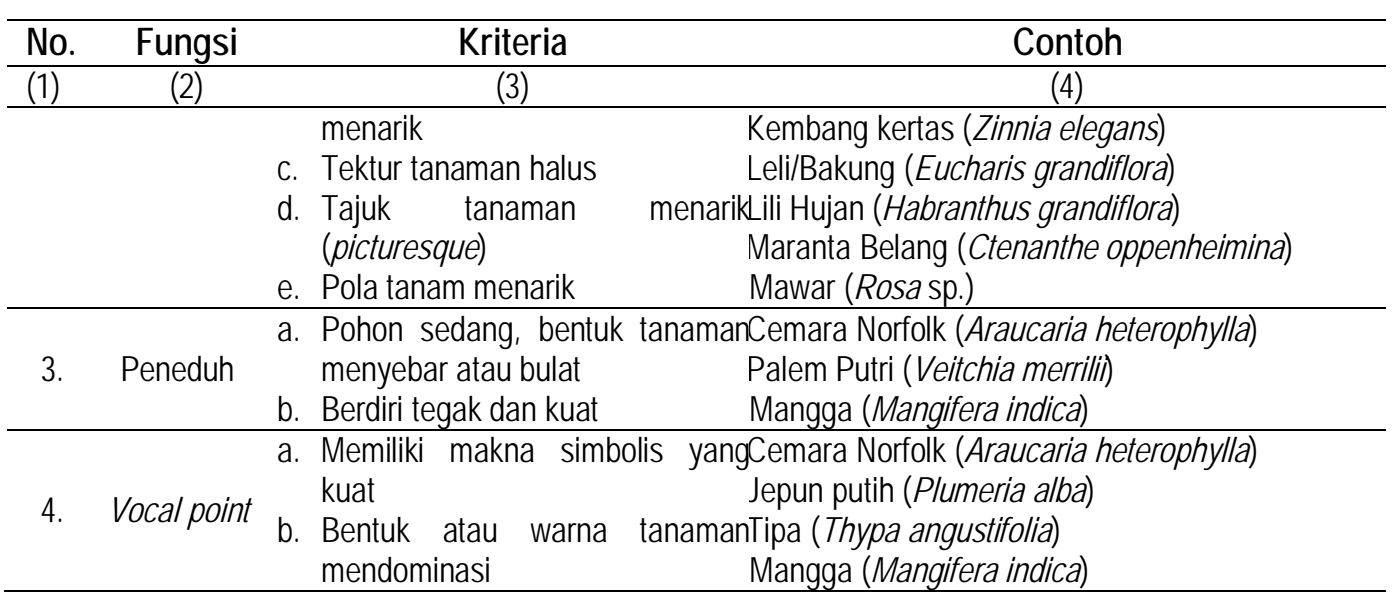

\subsubsection{Hubungan Ruang, Aktivitas, Fasilitas dan Tanaman}

Lansekap GKSMIT terbagi menjadi tiga ruang, meliputi Parahyangan, Pawongan dan Palemahan. Tiap ruang mewakili karakter aktivitas dari umat di lansekap GKSMIT. Penataan fasilitas dan tanaman dilakukan untuk membentuk suasana ruang sesuai dengan karakter dari tiap ruang tersebut, sehingga mendukung kegiatan umat di lansekap GKSMIT. Tabel 3 menampilkan hubungan ruang, aktivitas, fasilitas dan tanaman pada lansekap GKSMIT.

Tabel 3.Hubungan Ruang, Aktivitas, Fasilitas dan Tanaman

\begin{tabular}{|c|c|c|c|}
\hline No. & Ruang & Aktivitas & Fasilitas dan Tanaman \\
\hline (1) & (2) & (3) & (4) \\
\hline \multirow[t]{7}{*}{1.} & \multicolumn{3}{|c|}{ Parahyangan } \\
\hline & \multirow{4}{*}{$\begin{array}{l}\text { Banguna } \\
\text { n utama } \\
\text { GKSMIT }\end{array}$} & \multirow{2}{*}{ Misa Ekaristi } & Tempat duduk \\
\hline & & & Tanaman dengan fungsi vocal point \\
\hline & & \multirow{2}{*}{ Berdoa, merenung } & Tempat duduk \\
\hline & & & Tanaman dengan fungsi sebagai pembatas (border) \\
\hline & Gua & \multirow{2}{*}{ Berdoa } & Tempat duduk \\
\hline & Maria & & Tanaman dengan fungsi estetika \\
\hline \multirow[t]{5}{*}{2.} & \multicolumn{3}{|l|}{ Pawongan } \\
\hline & \multirow{2}{*}{ Aula } & \multirow{2}{*}{$\begin{array}{l}\text { Berkumpul, komunitas } \\
\text { GKSMIT }\end{array}$} & Tempat duduk \\
\hline & & & Tanaman dengan fungsi estetika \\
\hline & \multirow{2}{*}{$\begin{array}{l}\text { Sekretari } \\
\text { at pastor }\end{array}$} & \multirow{2}{*}{ Berkumpul } & Gazebo \\
\hline & & & Tanaman dengan fungsi vocal point, peneduh dan estetika \\
\hline \multirow[t]{8}{*}{3.} & \multicolumn{3}{|l|}{ Palemahan } \\
\hline & \multirow{5}{*}{$\begin{array}{l}\text { Area } \\
\text { parkir } \\
\text { motor }\end{array}$} & \multirow{2}{*}{$\begin{array}{l}\text { Memarkirkan } \\
\text { kendaraan }\end{array}$} & Tempat parkir \\
\hline & & & Tanaman dengan fungsi peneduh dan estetika \\
\hline & & \multirow{2}{*}{ Sanitasi } & Toilet \\
\hline & & & Tanaman dengan fungsi estetika \\
\hline & & $\begin{array}{l}\text { Memasuki bangunan } \\
\text { utama GKSMIT }\end{array}$ & Tanaman dengan fungsi vocal point dan estetika \\
\hline & \multirow{2}{*}{$\begin{array}{l}\text { Area } \\
\text { parkir } \\
\text { mobil }\end{array}$} & \multirow[b]{2}{*}{ Memarkir kendaraan } & Tempat parkir \\
\hline & & & Tanaman dengan fungsi estetika \\
\hline
\end{tabular}




\subsection{Perencanaan GKSMIT}

Perencanaan meliputi rencana penataan taman GKSMIT sebagai penciptaan suasana ruang. Gambar 4 menampilkan perencanaan lansekap GKSMIT.

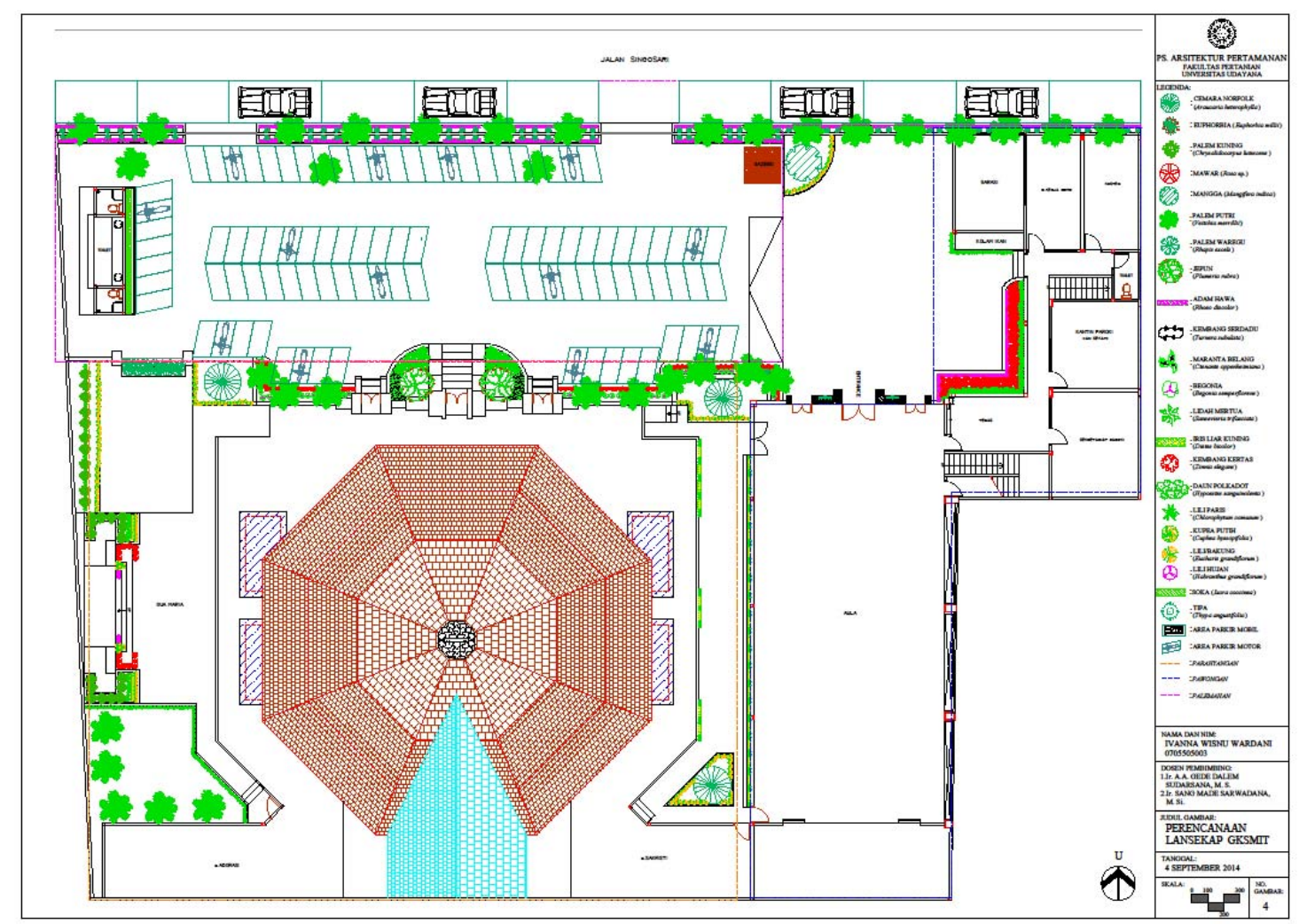

Gambar 4. Perencanaan Lansekap GKSMIT

\subsubsection{Parahyangan sebagai Konsep Perencanaan Ruang Sakral}

Implementasi Parahyangan pada lansekap GKSMIT berupa suasana yang menunjang kegiatan keagamaan. Serupa dengan masyarakat Bali yang mengimplementasikan Parahyangan kedalam bentuk kegiatan yang berkaitan dengan keyakinan dan keagamaan (Wiana, 2003). Penataan taman pada area bangunan gereja dibuat dengan bentukan sederhana. Tujuannya agar tidak mempengaruhi emosi pengguna. Cemara Norfolk (Araucaria heteropylla) dipilih menjadi vocal point pada area bangunan gereja dikombinasikan dengan Kupea Putih (Cuphea hyssopifolia). Ukuran Cemara Norfolk yang tinggi menjulang, mewakili keagungan Tuhan. Cemara Norfolk merupakan simbol suci bagi umat Kristiani yaitu sebagai lambang llahi Tuhan (Gray, 2013). Cemara Norfolk diletakkan pada lokasi perhubungan antara area bangunan gereja dengan area aula dan area ruang ganti Romo. Tujuannya untuk penanda bahwa pengguna berada di area suci sehingga memberi dampak kepada pengguna untuk menjaga sikap.

Iris Liar kuning (Dietes bicolor) dan Sansivera (Sansevieria trifasciata) ditanam di seputaran bangunan gereja yang ditata dengan bentuk linier sederhana. Kesan yang ingin 
disampaikan adalah rasa terisolasi namun tidak terpenjara. Warna kuning pada bunga Iris Liar kuning memberi kesan mulia serta untuk memecah monoton warna hijau tanaman. Gambar 5 menunjukkan ilustrasi rekomendasi penataan taman di area bangunan GKSMIT.

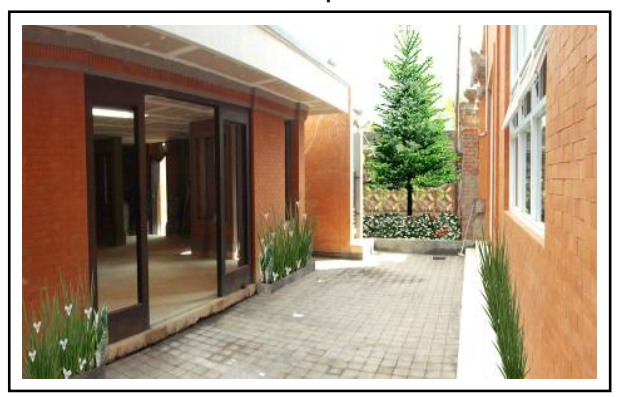

Gambar 5. Ilustrasi Rekomendasi Penataan Taman di Area Bangunan Utama GKSMIT

Area Gua Maria termasuk ruang Parahyangan. Kesan yang ingin disampaikan yaitu sosok dari Bunda Maria, sehingga taman didominasi dengan tanaman berbunga. Tanaman yang digunakan adalah Palem Kuning (Chrysalidocarpus lutescens), Mawar (Rosa sp), Sansivera, bunga Lili (Eucharis grandiflorum), Kupea Putih dan Lili Hujan (Habranthus grandiflorum). Pemilihan tanaman berdasarkan warna bunga tanaman yang mewakili warna liturgi. Makna simbolis Mawar dan bunga Lili melambangkan sosok dari Bunda Maria, Kupea Putih mewakili kesucian hati, dan Lili Hujan merepresentasikan kerendahan hati (Gray, 2013).

\subsubsection{Pawongan sebagai Konsep Perencanaan Ruang Sosial}

Ruang sosial meliputi bangunan aula dan ruang sekretariat paroki. Kegiatan yang berlangsung di ruang sosial berupa kegiatan dari komunitas GKSMIT dan interaksi sosial antar pengguna. Menurut Wiana (2003), Pawongan adalah hal-hal yang mengatur hubungan manusia dengan sesamanya agar harmonis. Berdasarkan penjelasan tersebut, maka Pawongan sesuai sebagai konsep perencanaan pada ruang sosial.

Aula gereja merupakan bangunan tertutup, sehingga kesan yang ingin disampaikan ditampilkan pada pintu masuk dan pintu keluar aula. Tipa (Thypa angustifolia) dimanfaatkan sebagai dekorasi untuk memperhalus perkerasan dari dinding bangunan. Fungsi lainnya untuk mengurangi silau dari paparan sinar matahari yang mengenai dinding luar bangunan (Booth, 1979). Tipa melambangkan semangat umat Katolik yang taat pada Yesus (Gray, 2013). Ilustrasi rekomendasi taman ditampilkan pada Gambar 6.

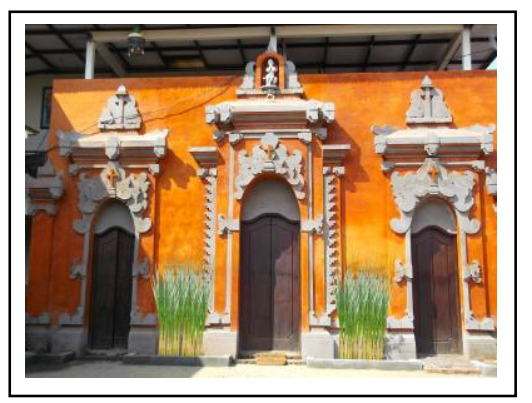

Gambar 6. Ilustrasi Rekomendasi Taman di Aula GKSMIT 
Saat keluar dari bangunan aula, arah pandangan pengguna akan tertuju pada area sekretariat pastor. Kesan yang ingin disampaikan yaitu perasaan gembira dan semarak sehingga diciptakan taman dengan komposisi Kembang kertas (Zinnia elegans) dan Sansivera sebagai elemen taman.

Setelah melewati area sekretariat pastor, pengguna akan berkumpul di gazebo sebelum menuju ke area tempat parkir. Kegiatan yang berlangsung di gazebo adalah sesama pengguna yang saling bersosialisasi. Mangga (Mangifera indica) digunakan sebagai vocal point pada taman di sekitar gazebo. Tujuannya untuk memberi bayang keteduhan sehingga menciptakan iklim mikro di gazebo. Mangga memiliki makna sebagai simbol ajaran agama yang berbuah banyak dan manis (Gray, 2013).

\subsubsection{Palemahan sebagai Konsep Perencanaan Ruang Servis}

Implementasi Palemahan pada lansekap GKSMIT sebagai tempat disediakannya fasilitas-fasilitas bagi pengguna. Sesuai dengan implementasi Palemahan oleh masyarakat Bali dalam bentuk tata ruang tradisional Bali yaitu Nista Mandala, merupakan tempat dilaksanakannya kegiatan pelayanan (Mugi, 2011 a).

Perencanaan taman bertujuan untuk menampilkan kesan relaksasi, sehingga taman nenggunakan sedikit variasi tanaman. Kesan relaksasi tercipta dengan komposisi ruang yang sederhana (Simonds, 1983). Euphorbia (Euphorbia millii), Palem Putri (Veitchia merrilli) dan Adam Hawa (Rhoeo discolor) sebagai elemen taman yang menandakan bahwa pengguna telah berada di lingkungan gereja. Kesan tersebut disampaikan dari tanaman Palem Putri sebagai simbol kemenangan Tuhan. Euphorbia memiliki karakter duri pada batangnya serta bunga berwarna merah yang melambangkan sengsara Yesus, sedangkan Adam Hawa merupakan tanaman simbol kekekalan hidup (Gray, 2013). Tanaman tersebut ditanam pada kedua sisi pagar gerbang GKSMIT. Tujuannya untuk memberi rasa nyaman bagi pengguna, karena tanaman tersebut berfungsi sebagai penghalau silau (Booth, 1979).

Kondisi tempat parkir motor yang merupakan ruang terbuka diatasi dengan tanaman Palem Putri. Tajuk Palem Putri berfungsi sebagai peneduh yang ditanam secara berbaris. Tanaman ini diletakkan pada tempat parkir motor karena melambangkan kemenangan Tuhan (Gray, 2013), sehingga memberi kesan bahwa umat telah berada di lingkungan gereja. Soka (Ixora coccinea) ditanam secara berbaris pada dinding bangunan toilet. Tanaman tersebut berfungsi untuk menyamarkan visual dari bangunan toilet yang terletak di area masuk gereja.

Tanaman Jepun (Plumeria rubra) berbunga putih menjadi vocal point pada area masuk GKSMIT. Tanaman tersebut ditanam pada pintu masuk menuju bangunan utama GKSMIT. Peran vocal point tersebut untuk mengumpulkan perhatian pengguna pada pintu masuk gereja. Warna putih dari bunga Jepun mememberi kesan bahwa pengguna akan memasuki bangunan gereja yang suci. Komposisi taman pada lokasi ini terdiri dari Daun Polkadot (Hypoestes sanguinolenta) dan Maranta Belang (Ctenanthe oppenheimiana). Gambar 7 menampilkan ilustrasi rekomendasi taman di area masuk GKSMIT. 


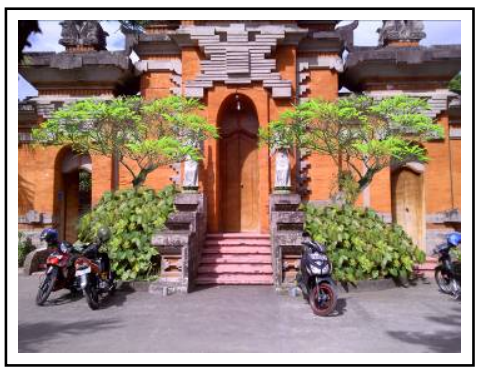

Gambar 7. Ilustrasi Rekomendasi Taman di Area Masuk GKSMIT

Sepanjang pintu masuk menuju bangunan utama GKSMIT terdapat dinding pagar. Area tersebut ditanam tanaman untuk memberi rasa nyaman bagi pengguna dengan komposisi Palem Putri, Begonia (Begonia semperflorens) dan Kembang Kertas (Zinnia elegans). Tujuannya untuk memperhalus perkerasan dari dinding pagar, sesuai dengan fungsi visual keindahan dari tanaman (Handayani, 2008).

\section{Simpulan dan Saran}

\subsubsection{Simpulan}

1. THK diaplikasikan sebagai konsep perencanaan lansekap GKSMIT dengan mengkategorikan kegiatan umat GKSMIT ke dalam tiga jenis karakter blok ruang, kemudian disesuaikan dengan tiga unsur THK.

2. Perencanaan lansekap GKSMIT dibentuk untuk menciptakan suasana pada masing-masing ruang di lansekap GKSMIT berdasarkan penggunaan ruang oleh umat GKSMIT.

3. Rekomendasi taman berdasarkan konsep perencanaan lansekap GKSMIT berupa taman dengan komposisi elemen tanaman yang berfungsi simbolis dan menonjolkan karakter tiap ruang pada lansekap GKSMIT. Pemilihan tanaman berdasarkan karakter ruang Parahyangan, Pawongan dan Palemahan.

\subsection{Saran}

Hasil penelitian dari perencanaan lansekap GKSMIT dapat digunakan sebagai rekomendasi bagi pengelola lansekap dalam penataan taman GKSMIT.

\section{Daftar Pustaka}

Booth, N. K. 1979. LARCH 204 Notebook. Ohio: The Ohio Univercity, Department of Landscape Architecture.

Fireza, D. 2008. Seri: Landscape by Belief; Religi sebagai Aspek dari Proses Perencaaan dan Desain Lansekap. Ruang Hijau. Tersedia online di: www.ruanghijau.wordpress.com/category/seri-landscape-by-belief.html (diakses 12 Januari 2014).

Gray, D. 2013. Christian Symbols, Chapter 14: Plants. Christians Symbols. Tersedia online di: www.christiansymbols.net (diakses 12 Januari 2014). 
Handayani, S. 2008. Bahan Ajar MK Arsitektur Lansekap D3: Elemen-Elemen Pendukung Lansekap. Bandung: Universitas Pendidikan Indonesia, Fakultas Pendidikan Teknologi dan Kejuruan, Jurusan Pendidikan Teknik Arsitektur

Koentjaraningrat. 1997. Kebudayaan dan Manusia di Indonesia. Djambatan, Jakarta.

Martasudjita, E. Pr. 1998. Seri Pendalaman Liturgi 2: Memahami Simbol-Simbol dalam Liturgi, Dasar Teologi Liturgis, Makna Simbol, Pakaian, Warna, Ruang, Tahun dan Musik. Kanisius, Yogyakarta.

Mugi, G. R. 19 April 2011 a. Falsafah dan Konsep Ruang Tradisional Bali. Institut Seni Indonesia Denpasar. Tersedia online di: www.jurnal.isi-dps.ac.id (diakses 12 Januari 2014).

Mugi, G. R. 13 Juni 2011 b. Harmonisasi Konsep dan Denah Oktagonal, Gereja Santa Maria Immaculata Tabanan. Paroki Tabanan. Tersedia online di: www.gerejakatoliktabanan.blogspot.com (diakses 12 Januari 2014).

Paulus Uskup Gereja Katolik. 4 Desember 1963. Dokumen Konsili Vatikan II, Konstitusi "SACROSANCTUM CONCILIUM" tentang Liturgi Suci.

Simonds, J.O. 1983. Landscape Architecture : The Shaping of Man's Natural Environment. McGraw-Hill Book Company Inc, New York.

Wiana, I K. 2003. "Menuju Bali Jagadhita : Tri Hita Karana Sehari-Hari". Bali, Menuju Jagadhita : Aneka Perspektif. Pustaka Bali Post, Denpasar. 